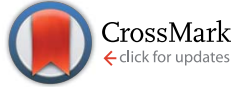

Cite this: RSC Adv., 2017, 7, 12827

Received 24th January 2017

Accepted 17th February 2017

DOI: $10.1039 / \mathrm{c} 7 \mathrm{ra01074e}$

rsc.li/rsc-advances

\section{A novel fluorescent sensor based on sulfur and nitrogen co-doped carbon dots with excellent stability for selective detection of doxycycline in raw milk $\dagger$}

\author{
Jinping Song, ${ }^{\text {ab }}$ Jing Li, ${ }^{\mathrm{c}}$ Ziying Guo, ${ }^{\mathrm{b}}$ Wen Liu, ${ }^{\mathrm{b}} \mathrm{Qi} \mathrm{Ma},{ }^{\text {,b }}$ Feng Feng*ab \\ and Chuan Dong*a
}

Casein was employed for the first time as a green carbon source to prepare water-soluble sulfur and nitrogen co-doped carbon dots (, $\mathrm{N}-\mathrm{CDS})$. The as-synthesized $\mathrm{S}, \mathrm{N}-\mathrm{CD}$ s were characterized by transmission electron microscopy, X-ray photoelectron spectroscopy, UV-Vis absorption spectroscopy, and fluorescence spectroscopy. Results showed that the as-prepared S,N-CDs had excellent stabilities under various external conditions, such as high ionic strength, different $\mathrm{pH}$ levels, UV light irradiation, and long storage duration. More importantly, we found that doxycycline (Dox) could result in an effective fluorescence quenching of $\mathrm{S}, \mathrm{N}-\mathrm{CDs}$ via a static quenching process. Thus, a sensitive and selective sensing system for Dox detection was developed. The linear range was $1.0 \times 10^{-7} \mathrm{M}$ to $1.0 \times 10^{-4} \mathrm{M}$, and the detection limit was $25 \mathrm{~nm}$. Furthermore, the proposed sensing system successfully detected Dox in raw milk samples. This research will demonstrate the feasibility and potential applications of carbon nanomaterials in food and medical monitoring fields.

\section{Introduction}

Doxycycline (Dox), a tetracycline (Tet) antibiotic, is extensively used to treat many infections, such as chronic prostatitis, respiratory tract infections, sinusitis, and sexually transmitted

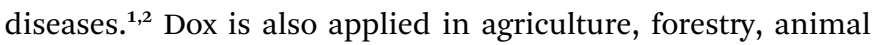
husbandry, and aquaculture as a fertilizer or animal food supplement because of its extensive antibacterial ability. ${ }^{3}$ However, Dox overuse may lead to serious environmental and food contamination, resulting in considerable risk to human health. ${ }^{4}$ Dox residues mainly exist in our daily food products, such as milk and honey. ${ }^{5,6}$ In worst-case scenarios, long-term and repeated intake of Dox affects the growth and formation of teeth. Therefore, the detection of Dox residues is important. In the past years, many analytical methods have been used to detect Dox, such as high-performance liquid chromatography, ${ }^{7-9}$ electroluminescent molecularly imprinted polymer

${ }^{a}$ Institute of Environmental Science, Shanxi University, Taiyuan, 030006, China.
E-mail: dc@sxu.edu.com
${ }^{b}$ College of Chemistry and Environmental Engineering, and Institute of Applied
Chemistry, Shanxi Datong University, Datong, Shanxi, 037009, China. E-mail:
maqihx@163.com; feng-feng64@263.net; Fax: +86-352-7158185; Tel: +86-352-
7158185
${ }^{c}$ School ofChemistry and Material Science, Shanxi Normal University, Linfen, 041001,
China

$\dagger$ Electronic supplementary information (ESI) available. See DOI: 10.1039/c7ra01074e membranes ${ }^{10}$ spectrofluorimetry, ${ }^{11}$ electrochemistry, ${ }^{12}$ immunosorbent assay, ${ }^{13}$ liquid chromatography-ultraviolet, and liquid chromatography-mass spectrometry. ${ }^{14}$ However, these methods require complicated sample pretreatment, expensive apparatus, and costly operation, limiting practical Dox detection in many fields. Thus, it is necessary to develop an alternative method for Dox detection with high sensitivity, selectivity, and convenience.

In recent years, considerable effort has been devoted to explore fluorescent probes with high selectivity and sensitivity for rapid analytical detection. Several carbonaceous nanomaterials, such as carbon nanotubes, graphene, fullerene and carbon quantum dots (CDs), have attracted extensive research interest. ${ }^{15-18}$ In comparison, CDs and functionalized CDs nanomaterials have exhibited great promise in designing fluorescent sensors and tuning fluorescence, due to low toxicity, low cost, low photobleaching, good aqueous solubility and excellent biocompatibility. ${ }^{19}$ For instance, Yang et al. realized the detection of tetracycline antibiotics by using fluorescent carbon nanoparticles prepared from a mixture of L-cysteine, diphosphorus pentoxide, and water. ${ }^{20}$ Subsequently, Yang et al. reported that CDs derived from rose flowers also successfully detected tetracycline antibiotics. ${ }^{21}$ However, Yang's results demonstrated that not only Dox can induce fluorescence quenching of the as-synthesized nitrogen-doped CDs but also other antibiotics, such as tetracycline (Tet), oxytetracycline, aureomycin, or chlortetracycline, can induce a similar response, 
implying the lack of specific selectivity. Thus, nitrogen-doped CDs are not conducive to the accurate analysis of a single component in complex samples.

In this study, casein, a protein derived from mammalian milk, was employed as a green carbon source for S,N-CDs preparation. The as-obtained S,N-CDs exhibited excellent stabilities in aqueous solution under an extensive $\mathrm{pH}$ range ( 2 to 11) and high ionic strength. More importantly, the assynthesized S,N-CDs probes exhibited excellent selectivity for distinguishing Dox from other tetracycline antibiotics.

\section{Experimental section}

\section{Materials and reagents}

Dox, Tet, oxytetracycline dihydrate (Oxy), and chloramphenicol (Chl) were acquired from Aladdin Reagents Company (Shanghai, China). Casein, concentrated sulfuric acid, metal salts $\left(\mathrm{Pb}\left(\mathrm{NO}_{3}\right)_{2}, \mathrm{Cu}\left(\mathrm{NO}_{3}\right)_{2}, \mathrm{HgCl}_{2}, \mathrm{NiSO}_{4}, \mathrm{BaCl}_{2}\right)$, isoniazid, Lglutamic acid, dopamine, vitamin $\mathrm{B}_{6}$, and tryptophan were purchased from Beijing Chemical Reagents Factory (Beijing, China). All chemicals were analytical reagent grade and used without further purification. Ultrapure water was used throughout all experiments.

\section{Synthesis of fluorescent S,N-CDs}

$\mathrm{S}, \mathrm{N}-\mathrm{CD}$ were prepared as follows: $1 \mathrm{~g}$ of casein was transferred to a $250 \mathrm{~mL}$ one-neck flask, then, $40 \mathrm{~mL}$ of concentrated sulfuric acid (98\%) was added. The mixture was vigorously stirred and reacted at $100{ }^{\circ} \mathrm{C}$ for $2 \mathrm{~h}$ and diluted with $100 \mathrm{~mL}$ deionized water. Then, the $\mathrm{pH}$ was adjusted to 7.0 with $\mathrm{NaOH}$ solution. Afterward, $300 \mathrm{~mL}$ of ethanol was added to the mixture. The mixture was allowed to precipitate overnight. The supernatant was collected and centrifuged at $10000 \mathrm{rpm}$ for $10 \mathrm{~min}$ to remove large carbon residues. The bulk of water and ethanol was removed by rotary evaporation. Further purification was performed with a dialysis membrane (molecular weight cut off $=1000$ ) for $48 \mathrm{~h}$ in the dark. Finally, a dark brown solution was obtained and stored at $4{ }^{\circ} \mathrm{C}$ for further characterization and use.

\section{Characterization}

Transmission electron microscopy images were taken with a JEOL JEM-2100 transmission electron microscope operating at an accelerated voltage of $200 \mathrm{kV}$. X-ray photoelectron spectra were obtained with a PHI-5400 electron spectrometer. UV-Vis absorption spectra were recorded with a Perkin-Elmer Lambda 35 UV-Vis spectrometer. Fluorescence measurements were conducted with a Cary Eclipse Fluorescence Spectrophotometer (Varian, Palo Alto, CA, USA) with a conventional $1 \mathrm{~cm} \times$ $1 \mathrm{~cm}$ quartz cell. Excitation and emission slit widths were both set at $10 \mathrm{~nm}$.

\section{Quantum yield measurements}

Quantum yield of the as-synthesized S,N-CDs was measured according to the procedure described previously. ${ }^{22}$ The reference standard was quinine sulfate in $0.1 \mathrm{M} \mathrm{H}_{2} \mathrm{SO}_{4}\left(\Phi_{\text {std }}=0.54\right.$ at
$350 \mathrm{~nm}$ ). Quantum yield values were calculated according to the following equation:

$$
\Phi_{\mathrm{x}}=\Phi_{\text {std }} \frac{I_{\mathrm{x}}}{A_{\mathrm{x}}} \frac{A_{\mathrm{std}}}{I_{\text {std }}} \frac{\eta_{\mathrm{x}}{ }^{2}}{\eta_{\mathrm{std}}{ }^{2}},
$$

where $\Phi$ is the quantum yield, $I$ is the measured integrated emission intensity, $A$ is the absorbance, and $\eta$ is the solvent refractive index. The subscripts "std" and " $x$ " refer to the reference standard and the tested substance, respectively.

\section{General procedure for Dox detection}

In a typical experiment, Dox solutions of different concentrations were added to $5 \mathrm{~mL}$ centrifuge tubes containing $100 \mu \mathrm{L}$ of $2.85 \mathrm{mg} \mathrm{mL}^{-1} \mathrm{~S}, \mathrm{~N}-\mathrm{CD}$ solution and diluted to $3 \mathrm{~mL}$ with $0.01 \mathrm{M}$ PBS buffer ( $\mathrm{pH}$ 7.4). The resulting mixtures were incubated for $5 \mathrm{~min}$ at room temperature and transferred into quartz cuvettes to obtain the corresponding fluorescence spectra.

\section{Dox detection in raw milk}

Raw milk samples were obtained from a local supermarket. Sample pretreatment was performed according to the protocol described by Le et al. ${ }^{23}$ In a typical experiment, $4 \mathrm{~mL}$ of raw milk was placed in a $50 \mathrm{~mL}$ beaker and diluted with $10 \mathrm{~mL}$ water. Then, $2 \mathrm{~mL}$ of $10 \%$ trichloroacetic acid was added to the diluted milk. The mixture was sonicated at $20{ }^{\circ} \mathrm{C}$ for $15 \mathrm{~min}$ and centrifuged at $13000 \mathrm{rpm}$ for $10 \mathrm{~min}$ to remove deposits. Supernatants were neutralized with $30 \% \mathrm{NaOH}$ solution and centrifuged at $20{ }^{\circ} \mathrm{C}$ for $10 \mathrm{~min}$ to remove deposits. Detection was performed with the final supernatant in accordance with the procedure described in Section 2.4. For the recovery experiments, raw milk was spiked with Dox, pretreated, and detected in accordance with the previously presented procedure.

\section{Results and discussion}

\section{Characterization and properties of $\mathrm{S}, \mathrm{N}-\mathrm{CDS}$}

Doped CDs are well-known nanomaterials because of their enhanced physical and chemical properties. However, some synthesis methods are complicated, time-consuming, expensive, or environmentally unfriendly, which not only restrict the mass production of CDs nanomaterials but also limit their extensive application in many fields. Thus, developing a simple, environmentally friendly, and low-cost synthesis approach for doped CDs is necessary. We need select a low-cost and green carbon source containing nitrogen and sulfur as the starting materials to avoid the complicated steps in introducing nitrogen and sulfur into CDs nanomaterials. Casein, a protein derived from mammalian milk, supplies various amino acids and carbohydrates ingredient, which entirely meet the above demand as green carbon sources. As shown in Scheme 1, the synthesis of S,N-CDs was conducted by acidic oxidation of casein in concentrated sulfuric acid. Actually, amino acids and carbohydrates served as the real carbon sources in the preparation process of $\mathrm{S}, \mathrm{N}-\mathrm{CDs}$.

Fig. 1 depicts the morphology and size distribution of the assynthesized S,N-CDs. S,N-CDs are monodispersed quasi- 


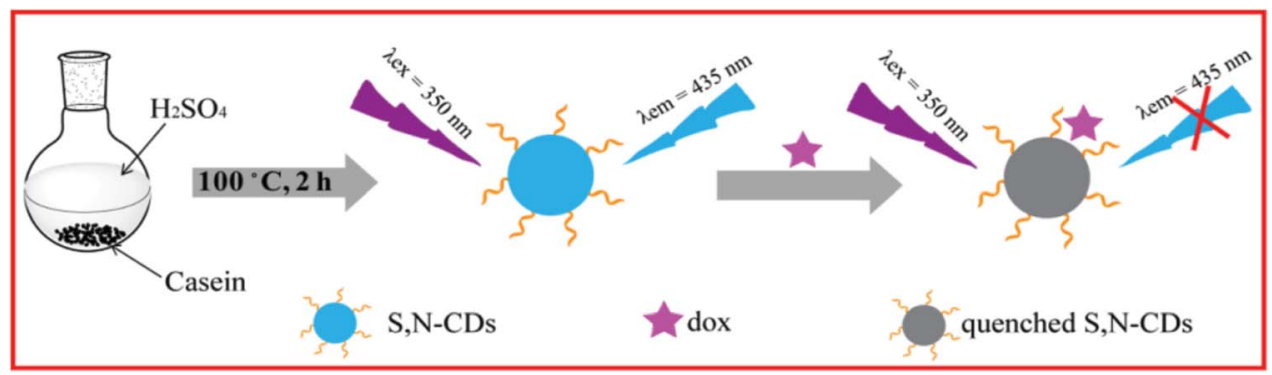

Scheme 1 Illustration of synthesis of S,N-CDs from casein and the principle of Dox detection.

spherical particles and have a relatively narrow size distribution range of $4.3 \mathrm{~nm}$ to $6.3 \mathrm{~nm}$ and an average diameter of $5.3 \mathrm{~nm}$. The high-resolution TEM (HRTEM) images (Fig. 1B) exhibit a well-resolved lattice fringe with a lattice spacing of $0.21 \mathrm{~nm}$ which can be attributed to the (110) facet of graphite. ${ }^{24}$ As shown in Fig. 1C, the size distribution of S,N-CDs conforms to a Gaussian distribution. The width at half maximum of the fitted Gaussian curve was calculated as $1.23 \mathrm{~nm}$, further implying that the as-synthesized S,N-CDs possess a narrow size distribution.

X-ray photoelectron spectroscopy was further performed to investigate the components of the as-synthesized S,N-CDs. As shown in Fig. 2A, two prominent peaks of $\mathrm{C}$ 1s (approximately $286 \mathrm{eV}$ ) and $\mathrm{O} 1 \mathrm{~s}$ (approximately $532 \mathrm{eV}$ ) were accompanied by three small peaks of $\mathrm{N}_{1 \mathrm{~s}}$ (approximately $400 \mathrm{eV}$ ), $\mathrm{S}_{2 \mathrm{~s}}$ (approximately $234 \mathrm{eV}$ ), and $\mathrm{S}_{2 \mathrm{p}}$ (approximately $169 \mathrm{eV}$ ) in the survey spectrum, indicating that the as-synthesized S,N-CDs mainly contained $\mathrm{C}, \mathrm{N}, \mathrm{O}$, and $\mathrm{S}$ atoms. The high-resolution spectrum of $\mathrm{C}_{1 \mathrm{~s}}$ (Fig. 2B) was deconvoluted into six peaks at 284.6, 285.4, 286.0, 286.6, 287.4, and $288.9 \mathrm{eV}$, corresponding to the $\mathrm{C}-\mathrm{C} / \mathrm{C}=$ $\mathrm{C}, \mathrm{C}-\mathrm{S}, \mathrm{C}-\mathrm{N}, \mathrm{C}-\mathrm{OH}, \mathrm{C}=\mathrm{O}$, and $\mathrm{O}-\mathrm{C}=\mathrm{O}$ peaks, respectively. ${ }^{25-27}$ In the high-resolution spectrum of $\mathrm{O}_{1 \mathrm{~s}}$ (Fig. 2C), the two main peaks corresponded to the $\mathrm{C}=\mathrm{O}$ and $\mathrm{C}-\mathrm{OH} / \mathrm{C}-\mathrm{O}-\mathrm{C}$ groups located at approximately 531.6 and $532.5 \mathrm{eV}^{26,28}$ The $\mathrm{N}_{1 \mathrm{~s}}$ spectrum exhibited three peaks at $399.7,400.6$, and $401.8 \mathrm{eV}$, which are ascribed to the $\mathrm{C}-\mathrm{N}-\mathrm{C}, \mathrm{N}-(\mathrm{C})_{3}$, and $\mathrm{N}-\mathrm{H}$ groups, respectively. ${ }^{29,30}$ The high-resolution spectrum of $\mathrm{S}_{2 \mathrm{p}}$ in Fig. 2E shows three peaks at 168.1,168.8, and $169.8 \mathrm{eV}$, which are associated with $-\mathrm{C}-\mathrm{SO}_{x^{-}}(x=2,3,4)$ species, such as sulfate or sulfonate. ${ }^{31}$
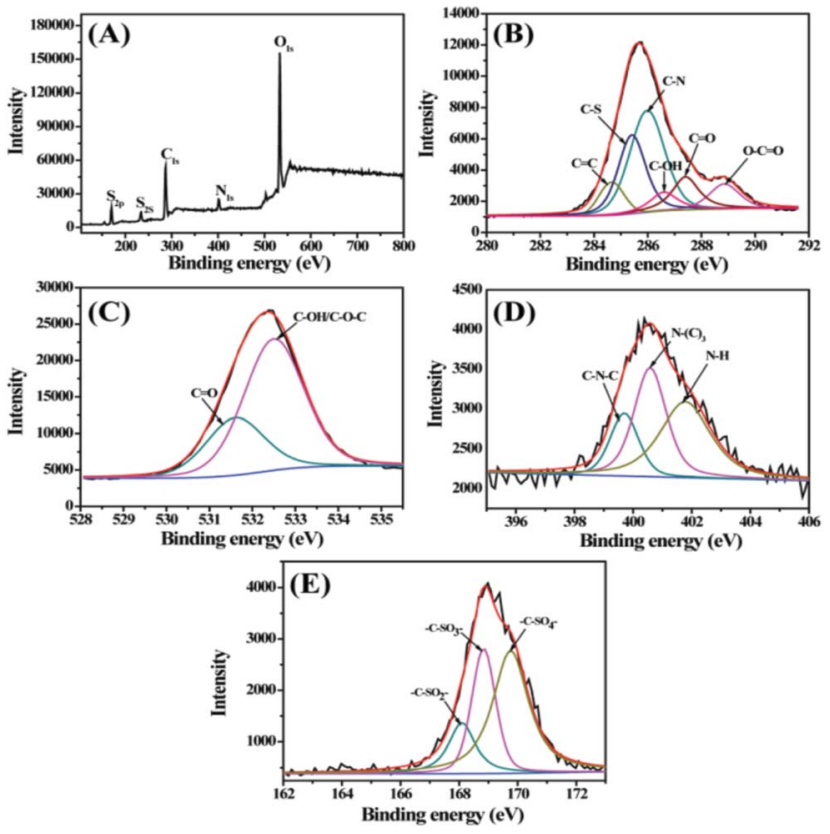

Fig. 2 (A) XPS survey spectra of S,N-CDs. High-resolution C 1s (B), O 1s (C), N 1s (D) and $S 2 p(E)$ peaks of the $S, N-C D s$.

The sulfur on the S,N-CDs may come from casein or the thermal dehydration of sulfuric acid. ${ }^{32}$

The as-prepared S,N-CDs aqueous solution was bright yellow and transparent under visible light, but emitted strong blue fluorescence under UV light (365 nm). The corresponding UV-
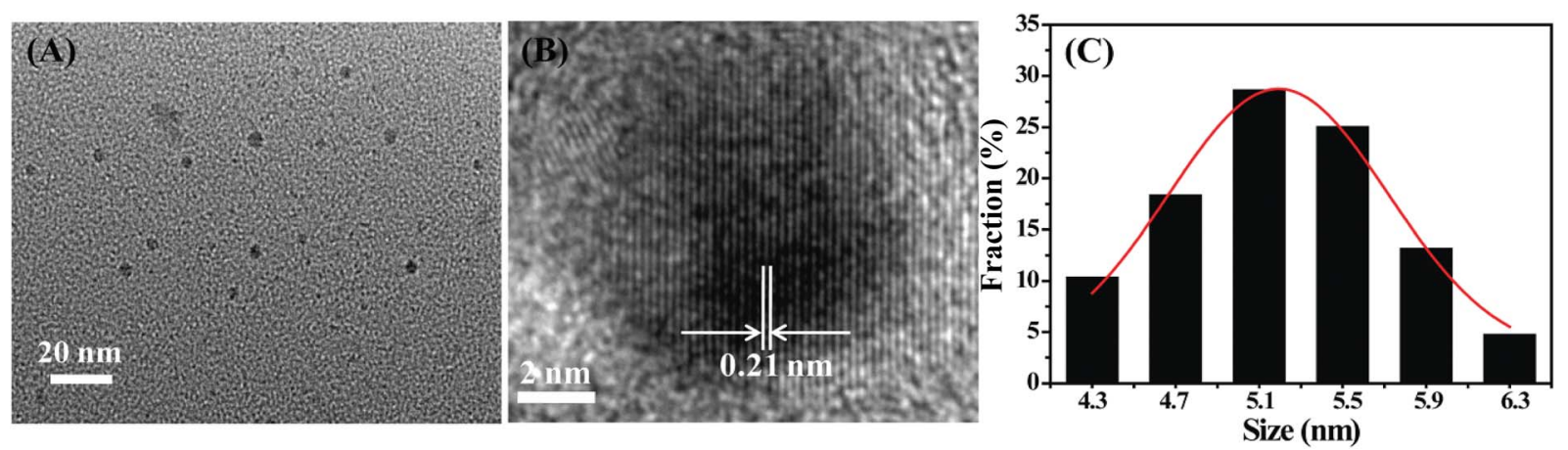

Fig. 1 TEM (A) and HRTEM (B) image of S,N-CDs. (C) Size distribution of S,N-CDs. 

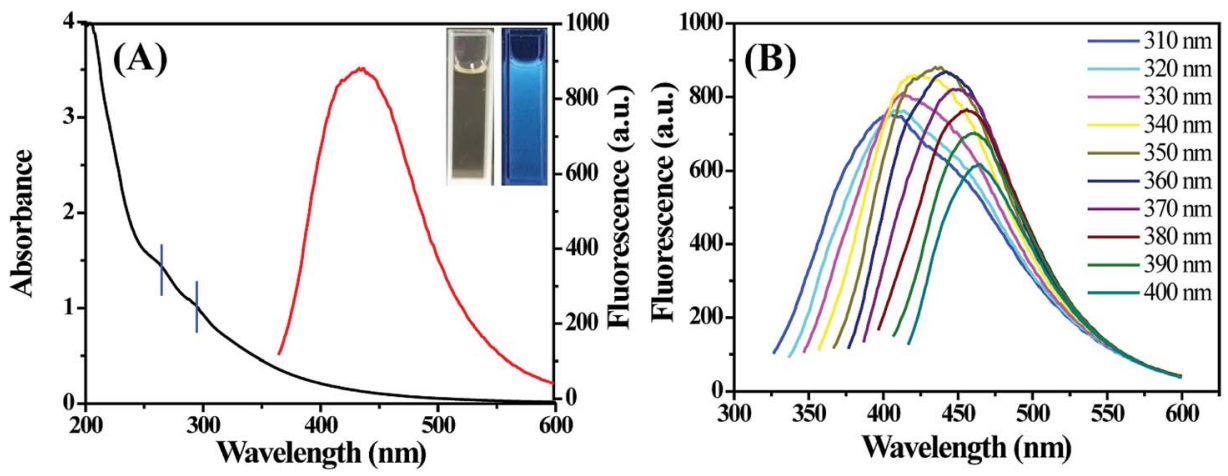

Fig. 3 (A) UV-Vis absorption (black line) and fluorescence (red line) spectra of S,N-CD solution (95 $\mu \mathrm{g} \mathrm{mL}^{-1}$ ). Inset is the corresponding photographs taken under sunlight (left) and $365 \mathrm{~nm}$ UV light (right). (B) Fluorescence spectra of S,N-CDs at $\lambda_{\text {ex }} 310-400 \mathrm{~nm}$, respectively.

Vis absorption and fluorescence spectra are shown in Fig. 3A. The UV-Vis spectrum of S,N-CDs showed two slight absorption peaks centered at 263 and $295 \mathrm{~nm}$, which was attributed to the $\pi-\pi^{*}$ transition of $\mathrm{C}=\mathrm{C}$ and $\mathrm{n}-\pi^{*}$ transition of $\mathrm{C}=\mathrm{O}$, respectively. ${ }^{33}$ In the fluorescence spectrum of S,N-CDs, the optimal excitation and emission wavelengths were located at 350 and $435 \mathrm{~nm}$, respectively. Moreover, the emission wavelength of S,NCDs was red shifted from $400 \mathrm{~nm}$ to $465 \mathrm{~nm}$ as the excitation wavelength moved from $310 \mathrm{~nm}$ to $400 \mathrm{~nm}$ (Fig. 3B). This excitation-dependent fluorescence behavior is attributed to diverse surface states and different particle sizes ${ }^{34}$ which will be useful in multicolor imaging applications. With quinine sulfate as the reference standard, the fluorescence quantum yield of S,N-CDs was estimated as $7.69 \%$.

\section{Stability of S,N-CDs}

When the as-prepared S,N-CDs are used for practical applications, the materials must be stable in the ambient environment. The effects of UV lamp irradiation and storage time on the fluorescence intensity of S,N-CDs were explored. Fluorescence intensity did not significantly decrease after $3 \mathrm{~h}$ under UV light irradiation (Fig. 4A) or after five days of storage (Fig. 4B), implying excellent photostability and storage stability of the S,N-CDs. As shown in Fig. 4C, fluorescence intensity remained constant with the increase in ionic strength. This characteristic is important because it is necessary for S,N-CDs to remain stable under physiological conditions during practical applications. Moreover, we also investigated the effect of $\mathrm{pH}$ on the stability
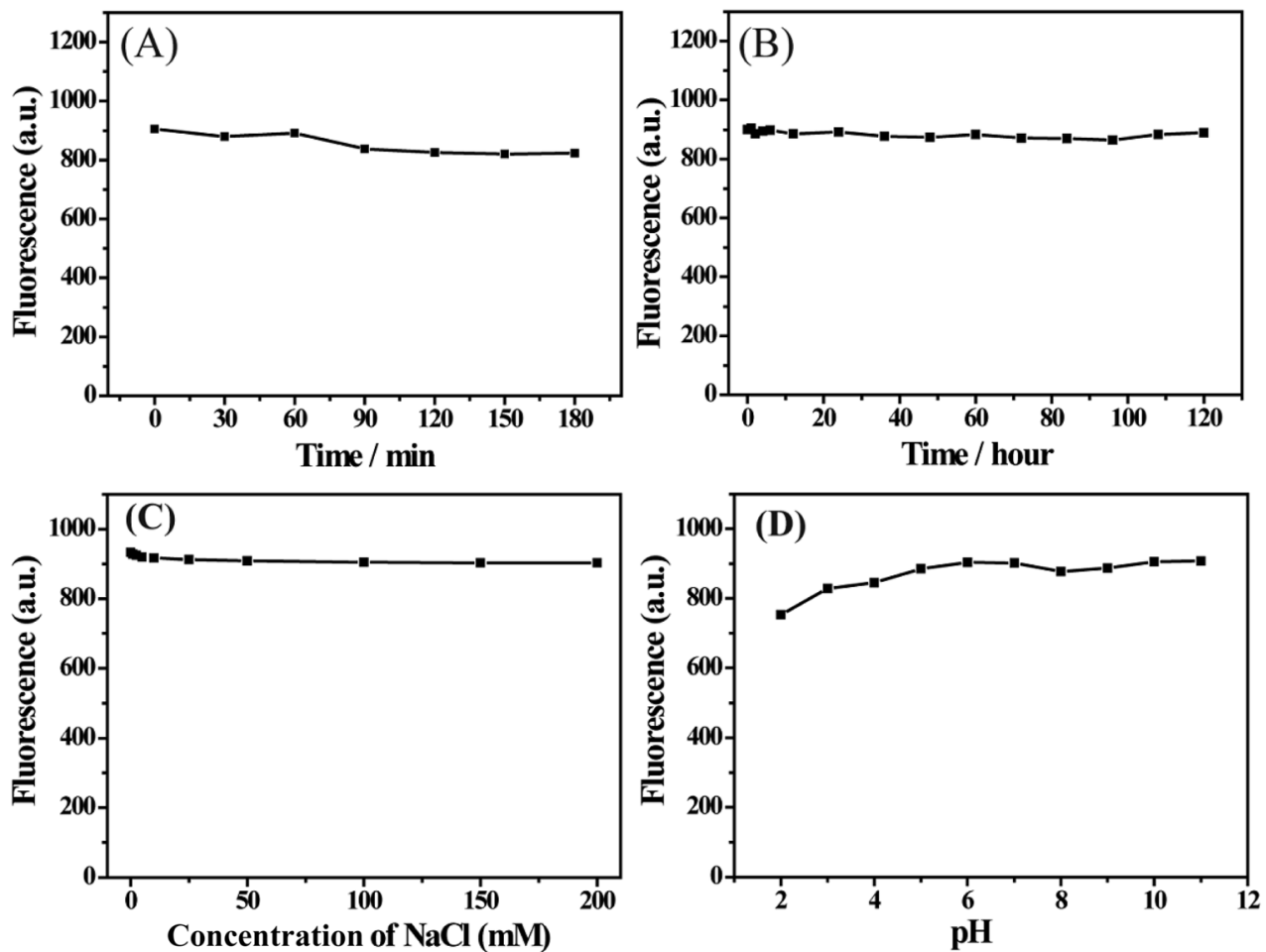

Fig. 4 Stability performance of S,N-CDs. Effect of UV lamp irradiation (A), storage time (B), ionic strength (C) and pH (D) on the fluorescence intensity of S,N-CDs. 

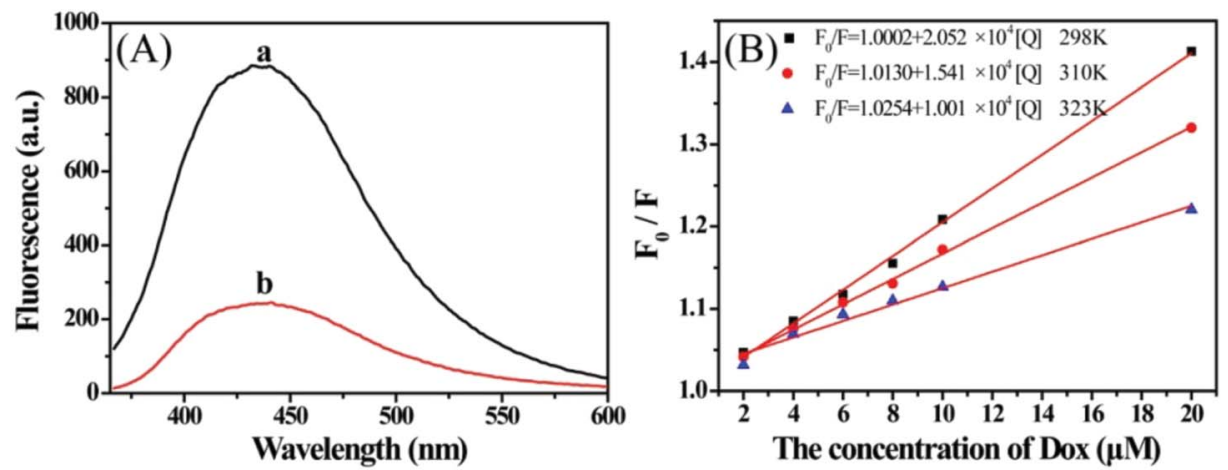

Fig. 5 (A) Fluorescence spectra of S,N-CDs in the absence (a) and presence (b) of Dox. (B) Stern-Volmer plots for S,N-CDs/Dox system at ( $298 \mathrm{~K},(\mathbf{O}) 310 \mathrm{~K}$ and $(\boldsymbol{\Delta}) 323 \mathrm{~K}$.

Table 1 Stern-Volmer quenching constants at different temperatures $(\mathrm{pH}=7.4)$

\begin{tabular}{llll}
\hline$T(\mathrm{~K})$ & $K_{\mathrm{SV}}\left(\mathrm{L} \mathrm{mol}^{-1}\right)$ & $K_{\mathrm{q}}\left(\mathrm{L} \mathrm{mol}^{-1} \mathrm{~s}^{-1}\right)$ & $R$ \\
\hline 298 & $2.052 \times 10^{4}$ & $4.253 \times 10^{12}$ & 0.9989 \\
310 & $1.541 \times 10^{4}$ & $3.194 \times 10^{12}$ & 0.9991 \\
323 & $1.001 \times 10^{4}$ & $2.075 \times 10^{12}$ & 0.9905
\end{tabular}

of S,N-CDs. As shown in Fig. 4D, the as-synthesized material presented a strong and stable fluorescence activity in the $\mathrm{pH}$ range of 2 to 11 , and $\mathrm{S}, \mathrm{N}-\mathrm{CD}$ still exhibited stable fluorescence even under extreme $\mathrm{pH}$ conditions. These results indicate that the as-synthesized S,N-CDs are highly stable.

\section{Dox sensing and the fluorescence quenching mechanism}

Fig. 5A depicts the fluorescence spectra of S,N-CDs in the absence and presence of Dox. S,N-CDs exhibited a strong fluorescence peak at $435 \mathrm{~nm}$ (Fig. 5, curve a). By contrast, Dox caused an obvious decrease in fluorescence intensity, implying that Dox effectively quenched S,N-CDs fluorescence. On the basis of the obvious fluorescence quenching, we constructed a sensitive fluorescence sensor for Dox detection. Scheme 1 presents the possible sensing principle for Dox detection.
We investigated the corresponding quenching constants at different temperatures by using the Stern-Volmer equation to understand the detailed quenching mechanism between S,NCDs and Dox: ${ }^{35}$

$$
F_{0} / F=1+K_{\mathrm{SV}}[\mathrm{Q}]=1+K_{\mathrm{q}} \tau_{0}[\mathrm{Q}]
$$

where $F$ and $F_{0}$ are the fluorescence intensities of S,N-CDs at $435 \mathrm{~nm}$ in the presence and absence of Dox, respectively, $K_{\mathrm{SV}}$ is the Stern-Volmer quenching constant, $K_{\mathrm{q}}$ is the bimolecular reaction rate constant, [Q] is the Dox concentration, and $\tau_{0}$ is the S,N-CDs lifetime in the absence of any quencher. In this research, $\tau_{0}$ of S,N-CDs was estimated as 4.8249 ns. Fig. 5B depicts the Stern-Volmer plots for the S,N-CDs/Dox system at different temperatures. The corresponding Stern-Volmer constants at different temperatures are shown in Table $1 . K_{\mathrm{SV}}$ decreased with the increase in temperature, indicating that the fluorescence quenching process followed a static quenching mechanism. $^{35}$

\section{Analytical detection of Dox by S,N-CDs}

The effect of reaction time on the fluorescence quenching of S,NCDs in the presence of Dox was further investigated to determine the optimal response time of the fluorescence sensor. As shown in
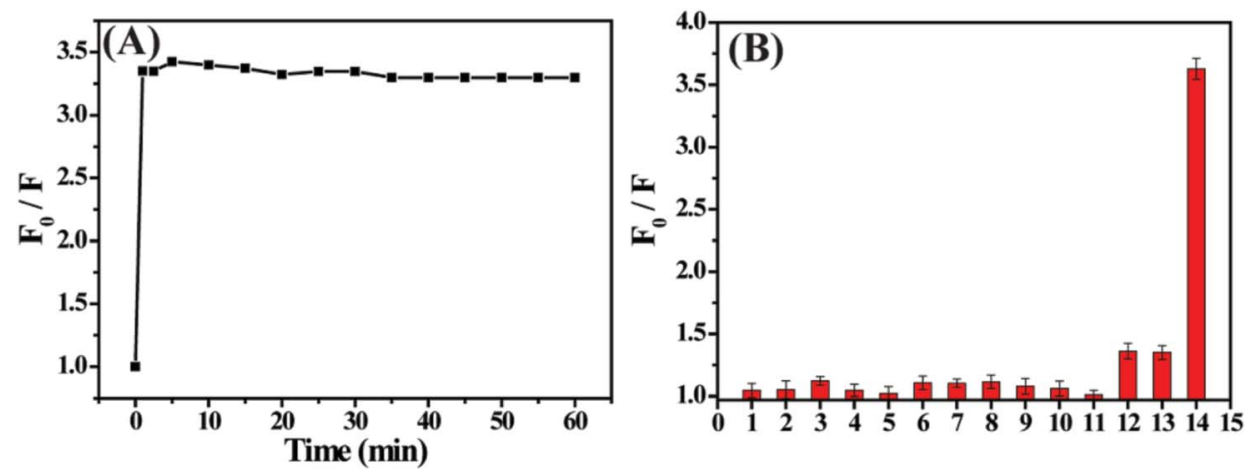

Fig. 6 (A) Effect of reaction time on fluorescence quenching of the S,N-CDs/Dox system. (B) Fluorescence intensity ratios $\left(F_{0} / F\right)$ of $S, N-C D s$ in the presence of different targets (1-14: isoniazid, L-glutamic acid, dopamine, vitamin $\mathrm{B}_{6}$, tryptophan, $\mathrm{Pb}^{2+}, \mathrm{Cu}^{2+}, \mathrm{Hg}^{2+}, \mathrm{Ni}^{2+}, \mathrm{Ba}^{2+}, \mathrm{Chl}^{2} \mathrm{Tet}, \mathrm{Oxy}$ and Dox). 

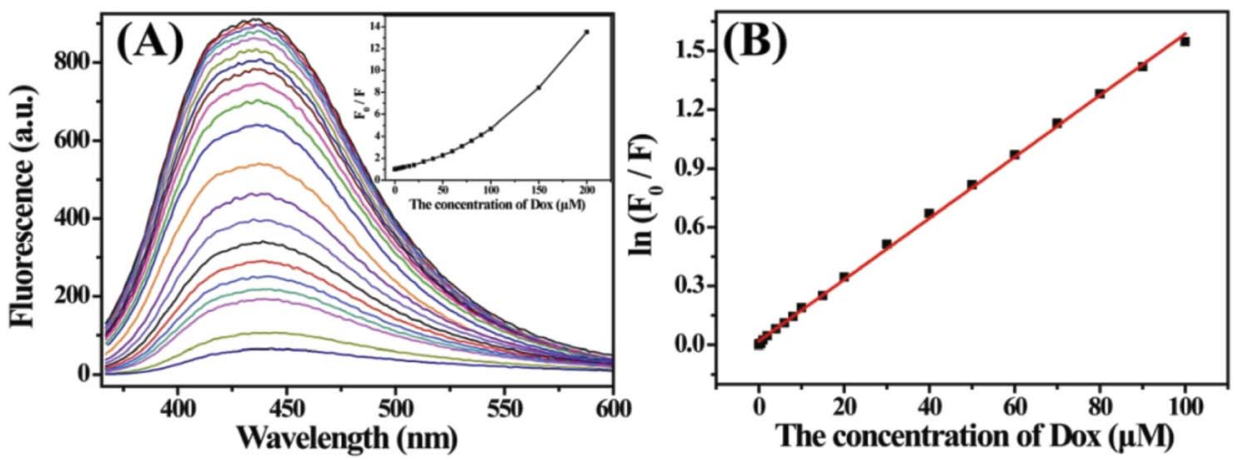

Fig. 7 (A) Fluorescence spectra of S,N-CDs $\left(95 \mu \mathrm{g} \mathrm{mL}^{-1}\right)$ in the presence of different concentration of Dox in $0.01 \mathrm{M} \mathrm{PBS}$ buffer (pH $\left.=7.4\right)$. Inset is the relationship between $F_{0} / F$ and the concentration of Dox. (B) The linear plot between $\ln \left(F_{0} / F\right)$ and the concentration of Dox.

Fig. 6A, the fluorescence intensity of S,N-CDs decreased rapidly after incubation for $1 \mathrm{~min}$ and became almost constant. We selected $5 \mathrm{~min}$ as the optimum reaction time in subsequent experiments to obtain stable and accurate experimental results.

The selectivity of S,N-CDs toward different targets was also investigated. As depicted in Fig. 6B, Dox had a significant quenching effect on the fluorescence of S,N-CDs, whereas Tet and Oxy only had slight effects. By contrast, no significant decrease in fluorescence was observed in the presence of other target molecules, such as isoniazid, dopamine, tryptophan, vitamin $\mathrm{B}_{6}$, $\mathrm{L}^{-}$ glutamic acid, $\mathrm{Pb}^{2+}, \mathrm{Cu}^{2+}, \mathrm{Hg}^{2+}, \mathrm{Ni}^{2+}, \mathrm{Ba}^{2+}$ and $\mathrm{Chl}$. These results indicate that the proposed assay method possesses outstanding selectivity and specificity for Dox detection. It is well known that the three antibiotics (Dox, Oxy and Tet) have a similar chemical structure (Fig. 1S $\dagger$ ), however, they demonstrated a different fluorescence quenching ability towards S,N-CDs. A possible explanation may be ascribed to the molecular structure of tetracycline antibiotics. According to the reported literature, ${ }^{36,37}$ at $\mathrm{pH}$ $=7.4$, the $\mathrm{OH}$ groups (the enolic site at $\mathrm{C} 3$, the phenolic proton at C10, or the dimethylammonium group) would be deprotonated, tetracycline antibiotics exhibited negative charges, and also bring about a "twisted" conformation. In this "twisted" conformation, $\mathrm{Cl}, \mathrm{C} 2, \mathrm{C} 3$, Camide, and $\mathrm{C} 4$ lie above the plane of the $\mathrm{BCD}$ rings, and the dimethylammonium group projects away from the rest of the molecule, ${ }^{36,37}$ which would bring about larger steric hindrance to impede the interaction between the right part of the tetracycline antibiotics and the proper recognition sites of S,N-CDs. In addition, the $\mathrm{OH}$ group on $\mathrm{C} 6$ can be deprotonated for Tet and Oxy, it would cause strong electrostatic repulsion and decrease the chances of the interactions between S,N-CDs and Tet or Oxy. However, it was noted there is not $\mathrm{OH}$ group on $\mathrm{C} 6$ in the structure of Dox. Thus, it provides more the chances for the interactions between S,N-CDs and Dox, leading to the excellent selectivity ability for Dox.

Fig. 7 shows the fluorescence quenching spectra of S,N-CDs in the presence of various Dox concentrations. The fluorescence intensity of S,N-CDs at $435 \mathrm{~nm}$ gradually decreased with the increase in Dox concentrations in the range of $0 \mathrm{M}$ to $2.0 \times$ $10^{-4} \mathrm{M}$. The inset presents the relationship between relative fluorescence ratio $\left(F_{0} / F\right)$ and Dox concentration. Strong linear responses between $\ln \left(F_{0} / F\right)$ and Dox concentration were obtained in the range of $1.0 \times 10^{-7} \mathrm{M}$ to $1.0 \times 10^{-4} \mathrm{M}$ (Fig. 7B). The corresponding linear regression equation is $\ln \left(F_{0} / F\right)=$ $0.01568 \times C(\mu \mathrm{M})+0.01883(r=0.9995)$. The detection limit was $25 \mathrm{nM}(\mathrm{S} / \mathrm{N}=3)$, which is comparable with the results reported in previous studies (Table 2).

\section{Dox detection in food samples}

We used the proposed method to detect Dox in raw milk to investigate the applicability of the as-synthesized S,N-CDs for

Table 2 Comparison of different methods for Dox detection

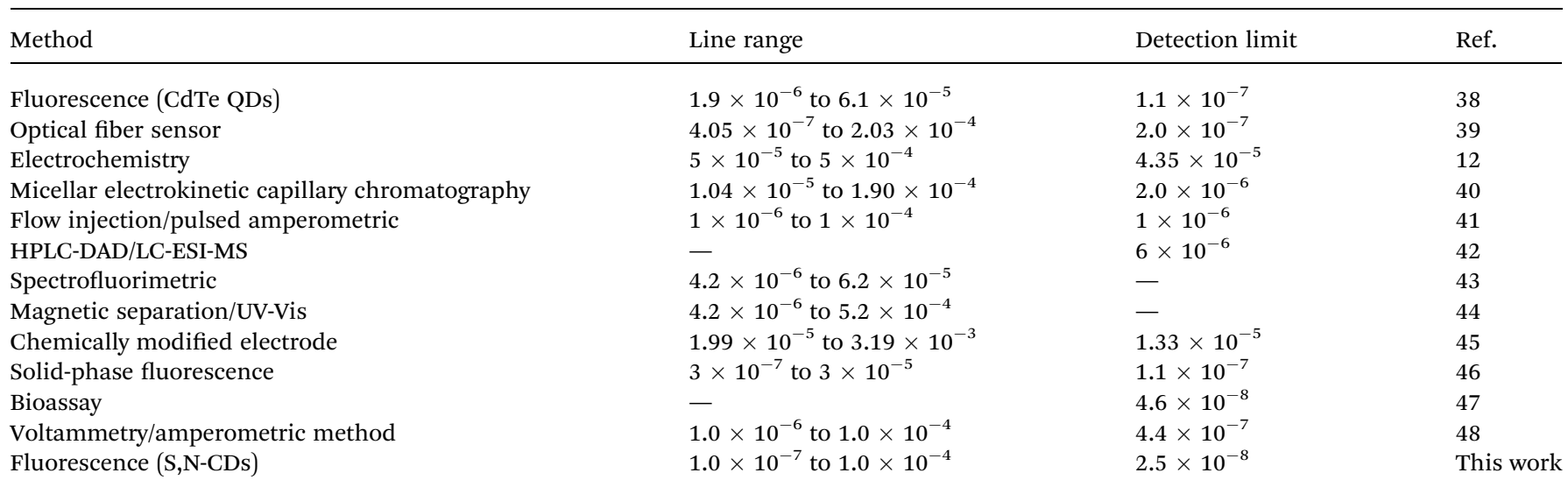


Table 3 Application of the proposed method for the determination of Dox in raw milk samples spiked with different concentrations of Dox ( $n$ =3)

\begin{tabular}{lllll}
\hline Sample & $\begin{array}{l}\text { Added Dox } \\
(\mu \mathrm{M})\end{array}$ & $\begin{array}{l}\text { Measured Dox } \\
(\mu \mathrm{M})\end{array}$ & $\begin{array}{l}\text { Recovery } \\
(\%)\end{array}$ & $\begin{array}{l}\text { RSD } \\
(\%)\end{array}$ \\
\hline \multirow{2}{*}{ Raw milk } & 0 & Not detected & - & - \\
& 3.27 & 3.31 & 101.3 & 1.42 \\
& 5.00 & 4.89 & 97.7 & 2.91 \\
& 32.68 & 31.48 & 96.3 & 3.15
\end{tabular}

Dox detection in real food samples. Raw milk was spiked with known quantities of Dox. Afterward, mixed samples were pretreated and analyzed according to the protocol described in Sections 2.5 and 2.6. As shown in Table 3, the recovery rates ranged from $96.3 \%$ to $101.3 \%$, whereas the relative standard deviations ranged from $1.42 \%$ to $3.15 \%$, implying that the proposed detection method has good reliability and excellent accuracy. Moreover, the entire experimental process, including the sample pretreatment procedure and analysis stage, only required $1 \mathrm{~h}$, indicating that our method can be used for rapid Dox detection in raw milk samples.

\section{Conclusion}

In summary, S,N-CDs with excellent stabilities were synthesized by carbonization of casein in concentrated sulfuric acid. The asprepared S,N-CDs emitted bright blue fluorescence and exhibited monodispersed quasi-spherical morphology with a size distribution of $4.3 \mathrm{~nm}$ to $6.3 \mathrm{~nm}$. Without further chemical modifications, the as-synthesized S,N-CDs were successfully utilized to develop a sensitive and selective sensing system for Dox detection in raw milk samples. This research may extend the potential application of CDs nanomaterials in food and medical monitoring fields because of their low-cost and simpler synthesis procedure and their extraordinary selectivity and sensitivity.

\section{Acknowledgements}

This work was supported by the National Natural Science Foundation of China (21301111), the Natural Science Foundation of Shanxi Province of China (2015011017, 2015021049), and Scientific and Technological Innovation Programs of Higher Education Institutions in Shanxi (2015181), the Industrial Science and Technology Project of Datong City (2015019), Research Project Supported by Shanxi Scholarship Council of China (2016-105).

\section{Notes and references}

1 P. J. Ramesh, K. Basavaiah and N. Rajendraprasad, Acta Pharm., 2010, 60, 445-454.

2 M. Augenbraun, L. Bachmann, T. Wallace, L. Dubouchet, W. McCormack and E. W. Hook, Sex. Transm. Dis., 1998, 25, 1-4.
3 B. A. Cunha, C. M. Sibley and A. M. Ristuccia, Ther. Drug Monit., 1982, 4, 115-135.

4 S. G. Bryant, S. Fisher and R. M. Kluge, Pharmacotherapy, 1987, 7, 125-129.

5 S. Croubels, C. Vanpeteghem and W. Baeyens, Analyst, 1994, 119, 2713-2716.

6 M. Jeon and I. R. Paeng, Anal. Chim. Acta, 2008, 626, 180-185.

7 E. Angelakis, N. Armstrong, C. Nappez, M. Richez, E. Chabriere and D. Raoult, J. Infect., 2015, 71, 511-517.

8 S. M. Sunarić, M. S. Denić, Z. Z. Bojanić and V. V. Bojanić, J. Chromatogr. B: Anal. Technol. Biomed. Life Sci., 2013, 939, 1722.

9 H. T. Lu, Y. Jiang, H. B. Li, F. Chen and M. H. Wong, Chromatographia, 2004, 60, 259-264.

10 S. Li, J. Li, Q. Lin and X. Wei, Analyst, 2015, 140, 4702-4707. 11 C. Q. Jiang and N. Zhang, J. Pharm. Biomed. Anal., 2004, 35, 1301-1306.

12 B. Gürler, S. P. Özkorucuklu and E. Kır, J. Pharm. Biomed. Anal., 2013, 84, 263-268.

13 J. Adrian, F. Fernandez, F. Sanchez-Baeza and M. P. Marco, J. Agric. Food Chem., 2012, 60, 3837-3846.

14 A. Gajda, A. Posyniak, J. Zmudzki and G. Tomczyk, J. Chromatogr. B: Anal. Technol. Biomed. Life Sci., 2013, 928, 113-120.

15 C. Jiang, A. Saha, C. Xiang, C. C. Young, J. M. Tour, M. Pasquali and A. A. Marti, ACS Nano, 2013, 7, 4503-4510.

16 K. Han, P. Miao, H. Tong, T. Liu, W. Cheng, X. Zhu and Y. Tang, Appl. Phys. Lett., 2014, 104, 053101.

17 C. Jiang, A. Saha, C. C. Young, D. P. Hashim, C. E. Ramirez, P. M. Ajayan, M. Pasquali and A. A. Marti, ACS Nano, 2014, 8, 9107-9112.

18 A. Saha, C. Jiang and A. A. Marti, Carbon, 2014, 79, 1-18.

19 Y. Dong, R. Wang, W. Tian, Y. Chi and G. Chen, RSC Adv., 2014, 4, 3701-3705.

20 X. Yang, Y. Luo, S. Zhu, Y. Feng, Y. Zhuo and Y. Dou, Biosens. Bioelectron., 2014, 56, 6-11.

21 Y. Feng, D. Zhong, H. Miao and X. Yang, Talanta, 2015, 140, 128-133.

22 N. Dhenadhayalan and K. C. Lin, Sci. Rep., 2015, 5, 10012.

23 T. Le, Z. Zhao, W. Wei and D. Bi, Food Chem., 2012, 134, 2442-2446.

24 Y. Dong, R. Wang, H. Li, J. Shao, Y. Chi, X. Lin and G. Cheng, Carbon, 2012, 50, 2810-2815.

25 C. Mattevi, G. Eda, S. Agnoli, S. Miller, K. A. Mkhoyan, O. Celik, D. Mastrogiovanni, G. Granozzi, E. Garfunkel and M. Chhowalla, Adv. Funct. Mater., 2009, 19, 2577-2583.

26 S. Liu, J. Tian, L. Wang, Y. Zhang, X. Qin, Y. Luo, A. M. Asiri, A. O. Al-Youbi and X. Sun, Adv. Mater., 2012, 24, 2037-2041.

27 J. P. Paraknowitsch, Y. J. Zhang, B. Wienert and A. Thomas, Chem. Commun., 2013, 49, 1208-1210.

28 W. Lu, X. Qin, S. Liu, G. Chang, Y. Zhang, Y. Luo, A. M. Asiri, A. O. Al-Youbi and X. Sun, Anal. Chem., 2012, 84, 5351-5357. 29 Z. Qian, J. Ma, X. Shan, H. Feng, L. Shao and J. Chen, Chem.Eur. J., 2014, 20, 2254-2263.

30 X. Chen, Q. Jin, L. Wu, C. Tung and X. Tang, Angew. Chem., Int. Ed., 2014, 53, 12542-12547. 
31 D. Sun, R. Ban, P. H. Zhang, G. H. Wu, J. R. Zhang and J. J. Zhu, Carbon, 2013, 64, 424-434.

32 S. Chandra, P. Patra, S. H. Pathan, S. Roy, S. Mitra, A. Layek, R. Bhar, P. Pramanik and A. Goswami, J. Mater. Chem. B, 2013, 1, 2375-2382.

33 Q. Mei and Z. Zhang, Angew. Chem., Int. Ed., 2012, 51, 56025606.

34 X. Li, H. Wang, Y. Shimizu, A. Pyatenko, K. Kawaguchi and N. Koshizaki, Chem. Commun., 2011, 47, 932-934.

35 H. Xu, X. Yang, G. Li, C. Zhao and X. Liao, J. Agric. Food Chem., 2015, 63, 6707-6714.

36 F. C. machado, C. Demicheli, A. Garnier-Suillerot and H. Beraldo, J. Inorg. Biochem., 1995, 60, 163-173.

37 W. Chen and C. Huang, Environ. Sci. Technol., 2009, 43, 401407.

38 J. Tashkhourian, G. Absalan, M. Jafari and S. Zare, Spectrochim. Acta, Part A, 2016, 152, 119-125.

39 W. Liu, Y. Wang, J. Tang, G. Shen and R. Yu, Analyst, 1998, 123, 365-369.
40 R. Injac, J. Kac, S. Kreft and B. Strukelj, Anal. Bioanal. Chem., 2007, 387, 695-701.

41 T. Charoenraks, S. Palaharn, K. Grudpan, W. Siangproh and O. Chailapakul, Talanta, 2004, 64, 1247-1252.

42 J. Fiori, G. Grassigli, P. Filippi, R. Gotti and V. Cavrini, J. Pharm. Biomed. Anal., 2005, 37, 979-985.

43 H. M. Lotfy, M. A. Hegazy, S. Mowaka and E. H. Mohamed, Spectrochim. Acta, Part A, 2016, 153, 321-332.

44 M. Ghaemi and G. Absalan, J. Iran. Chem. Soc., 2015, 12, 1-7. 45 Y. M. Issa, H. M. Abdel-Fattah and N. B. Abdel-Moniem, Int. J. Electrochem. Sci., 2013, 8, 9578-9592.

46 I. I. Parashchenko, T. D. Smirnova, S. N. Shtykov, V. I. Kochubei and N. N. Zhukova, J. Anal. Chem., 2013, 68, 112-116.

47 W. Kleibeuker, X. Zhou, M. Centlivre, N. Legrand, M. Page, N. Almond, B. Berkhout and A. T. Das, Hum. Gene Ther., 2009, 20, 524-530.

48 D. Vega, L. Agüí, A. González-Cortés, P. Yáñez-Sedeño and J. M. Pingarrón, Anal. Bioanal. Chem., 2007, 389, 951-958. 